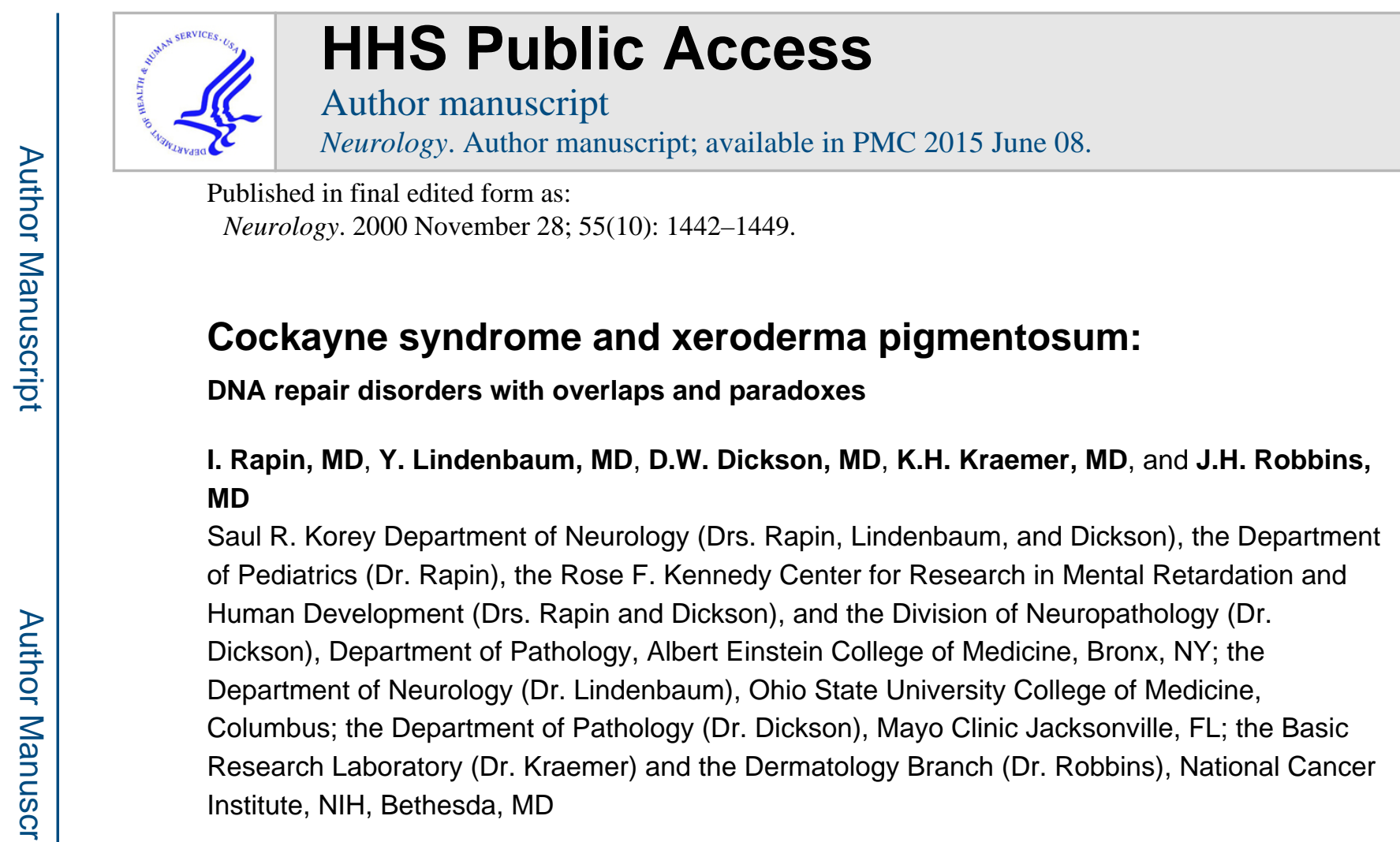

\title{
Abstract
}

Objectives-To review genetic variants of Cockayne syndrome (CS) and xeroderma pigmentosum (XP), autosomal recessive disorders of DNA repair that affect the nervous system, and to illustrate them by the first case of xeroderma pigmentosum-Cockayne syndrome (XP-CS) complex to undergo neuropathologic examination.

Methods-Published reports of clinical, pathologic, and molecular studies of CS, XP neurologic disease, and the XP-CS complex were reviewed, and a ninth case of XP-CS is summarized.

Results-CS is a multisystem disorder that causes both profound growth failure of the soma and brain and progressive cachexia, retinal, cochlear, and neurologic degeneration, with a leukodystrophy and demyelinating neuropathy without an increase in cancer. XP presents as extreme photosensitivity of the skin and eyes with a 1000-fold increased frequency of cutaneous basal and squamous cell carcinomas and melanomas and a small increase in nervous system neoplasms. Some $20 \%$ of patients with XP incur progressive degeneration of previously normally developed neurons resulting in cortical, basal ganglia, cerebellar, and spinal atrophy, cochlear degeneration, and a mixed distal axonal neuropathy. Cultured cells from patients with CS or XP are hypersensitive to killing by ultraviolet (UV) radiation. Both CS and most XP cells have defective DNA nucleotide excision repair of actively transcribing genes; in addition, XP cells have defective repair of the global genome. There are two complementation groups in CS and seven in XP. Patients with the XP-CS complex fall into three XP complementation groups. Despite their XP genotype, six of nine individuals with the XP-CS complex, including the boy we followed up to his death at age 6 , had the typical clinically and pathologically severe CS phenotype. Cultured

Copyright (@) 2000 by AAN Enterprises, Inc

Permissions \& Licensing Information about reproducing this article in parts (figures, tables) or in its entirety can be found online at: http://www.neurology.org/misc/about.xhtml\#permissions

Address correspondence and reprint requests to Dr. Isabelle Rapin, Room 807 Kennedy Center, Albert Einstein College of Medicine, 1410 Pelham Parkway South, Bronx, NY 10461; rapin@ aecom.yu.edu. 
skin and blood cells had extreme sensitivity to killing by UV radiation, DNA repair was severely deficient, post-UV unscheduled DNA synthesis was reduced to less than 5\%, and post-UV plasmid mutation frequency was increased.

Conclusions-The paradoxical lack of parallelism of phenotype to genotype is unexplained in these disorders. Perhaps diverse mutations responsible for UV sensitivity and deficient DNA repair may also produce profound failure of brain and somatic growth, progressive cachexia and premature aging, and tissue-selective neurologic deterioration by their roles in regulation of transcription and repair of endogenous oxidative DNA damage.

Cockayne syndrome (CS), ${ }^{1}$ xeroderma pigmentosum (XP) neurologic disease, ${ }^{2}$ the xeroderma pigmentosum- Cockayne syndrome (XP-CS) complex, ${ }^{3,4}$ and others are rare genetic disorders with striking somatic and neurologic involvement. The hallmark of this group of diseases is inadequate DNA repair. Cells of both CS and XP are characterized in tissue culture by hypersensitivity to killing by ultraviolet (UV) radiation but differ in some of their cardinal laboratory characteristics (table 1). Although CS and most XP cells have defective DNA repair of actively transcribed genes, only XP cells have low DNA repair in the genome overall, as measured, e.g., by unscheduled DNA synthesis after UV exposure.

CS and XP are clinically and genetically distinct disorders. Each is genetically heterogeneous and comprises a variety of clinical phenotypes. One of the unexplained and salient paradoxes about this group of disorders is that the phenotypes of individuals with XP-CS complex, which also vary a great deal, are overwhelmingly CS despite their XP genotypes. This article reviews each of these disorders in turn, with a focus on a boy who died of XP-G/CS whose case illustrates several of these paradoxes.

\section{Cockayne syndrome}

CS is a multisystem, autosomal, recessive disease (table 2). Its two hallmarks are profound postnatal growth failure of the soma and brain, associated with premature senescence and progressive multiorgan degeneration. ${ }^{5,6}$ There are two forms of CS that differ in their severities $^{7}$ : type I, a less severe form with survival into adolescence or young adult life, is linked to mutations of the CSA gene on chromosome 5; type II, a more prevalent severe infantile form, leads to earlier death and is linked to mutations of the CSB gene on chromosome 10q11. Two clinical variants of type II CS, the classic severe infantile variant and some cases of the cerebro-oculo-facial-skeletal (COFS) syndrome, are due to mutations of the CSB gene. ${ }^{8}$ The XP-CS complex, illustrated by our patient with XPG/CS, can result from mutations in any one of three XP genes; mutations in two result in a severe type II CS phenotype and mutations in the third in a mild type I CS phenotype.

Developmental features of CS include severe dwarfism and mental retardation. The brain is extraordinarily small but is not grossly malformed. This observation and the fact that head circumference is typically normal at birth indicate that failure of brain growth is mainly postnatal, in contrast to its prenatal occurrence in, for example, the recessive severe primary microcephalies ${ }^{9}$ and Seckel birdheaded dwarf syndrome. ${ }^{10}$ This timing makes it unlikely that the cause of the extreme micrencephaly of CS is premature curtailment of neurogenesis, disordered neuronal migration, or grossly aberrant connectivity. Interference with the 
proliferation, branching, and deployment of neuronal processes seems more plausible. Indeed, lamination of the neocortex, as well as neuronal size and configuration, are relatively preserved. Gandolfi et al. ${ }^{11}$ measured neuronal size and cell density in the right frontal gyrus and left parietal lobule of a 17-year-old girl with classic type I CS and did not find substantial differences from a control brain. This relatively normal structural brain development, including the neocortex, may account for one of the notable features of CS, commented on by Cockayne ${ }^{1}$ in his original 1936 description and by others (e.g., Neill and Dingwall ${ }^{12}$ and Brumback et al. ${ }^{13}$ ): namely, less profoundly impaired cognition and behavior than one might predict from the diminutive size of the brain (some 450 to 700 grams), together with remarkably preserved sociability and alertness.

The factor responsible for drastic failure of brain and somatic growth is unknown. Hormonal studies, such as glucose tolerance tests, basal or stimulated growth hormone levels, and responses to insulin, arginine, and glucagon have not revealed the causes of the dramatic dwarfing and cachexia. Although results of these studies were abnormal in some patients, a trial of growth hormone therapy in one patient did not result in significant growth. ${ }^{5}$

In addition to growth failure, there is also evidence in CS for a progressive deteriorating process, presumably related in some way to the defective DNA repair. Progression is indexed by advancing cachexia, worsening hearing and vision with small miotic pupils, cataracts, pigmentary retinopathy, optic atrophy, cutaneous sun sensitivity, and other systemic signs of premature aging. The facies becomes characteristically wizened with progressive loss of fat; deep set eyes, thin nose, and vermillion of the lips are seen, with severe early dental caries. There may be very premature arteriosclerosis, calcific vasculopathy (especially in the basal ganglia where it is visible on CT scans), meningeal fibrosis, excessive accumulation of lipofuscin in neurons, Alzheimer neurofibrillary tangles, and Hirano bodies. ${ }^{6}$ These features are not uniformly present and vary significantly in intensity. The possibility that low-pressure hydrocephalus may contribute to ventricular dilatation and clinical deterioration was raised in four patients with CS (three patients with presumed type I CS and an adult with the XP-CS complex). ${ }^{13}$ This was suggested by lack of sulcal dilatation, ventricular reflux, and delayed clearance on radionucleide cisternography; in addition, published postmortem studies of patients with CS have reported leptomeningeal fibrosis and patchy ependymal denudation with glial overgrowth (so-called granular ependymitis).

Myelin maintenance in both the CNS and peripheral nerves bears the brunt of the progressive pathology. In the brain it presents as a tigroid leukodystrophy with severe atrophy of white matter. There is gliosis and some neuronal loss in the cortex, basal ganglia, and, especially, in the cerebellum, where exuberant proliferation of apical dendrites of Purkinje cells ${ }^{6}$ and neuronal death by apoptosis have been documented. ${ }^{14}$ This widespread pathology explains the loss of motor milestones, with increasing spasticity, ataxia, and weakness. In peripheral nerves, loss of myelin is marked by slow conduction velocities. CSF protein levels are often elevated. Progressive high-tone hearing loss results from gradual degeneration of all the cellular elements of the cochlea, associated with secondary degeneration of the relays of the central auditory pathway, according to the quantitative analysis carried out by Gandolfi et al. ${ }^{11}$ in their 17 -year-old patient with CS. Advancing loss 
of vestibular function because of progressive cellular death in the vestibular labyrinth, added to the cerebellar degeneration, impaired somatosensory input from the neuropathy, and increasingly poor vision contributes to the ataxia of patients with CS.

Widespread gliosis supports an ongoing degenerative process. Astrocytes are pleomorphic, a few are multinucleated, and many are bizarre and irregularly shaped with swollen, lobulated, hyperchromatic nuclei. ${ }^{6,15}$ Similar bizarre reactive astrocytes, as well as dysmorphic Schwann and satellite cells in dorsal root ganglia are seen in ataxia-telangiectasia, a disorder with increased sensitivity to ionizing radiation and carcinogenesis, ${ }^{16}$ and in cultured fibroblasts of patients with tuberous sclerosis exposed to ionizing radiation. ${ }^{17}$ The bizarre astrocytes of CS also resemble those seen in glial neoplasms and in disorders caused by oncogenic viral infection (e.g., papovavirus). ${ }^{18}$ These glial lesions in CS may thus represent a preneoplastic alteration, even though CNS neoplasms have not been reported in patients with CS. This is in contrast to patients with XP, who have an approximately 10-fold increased risk of nervous system tumors, including astrocytomas, medulloblastomas, and schwannomas. ${ }^{19,20}$

\section{The cerebro-oculo-facial-skeletal syndrome}

The COFS syndrome is an autosomal recessive disease that shares clinical features with type II CS ${ }^{21}$ (see table 2). Seven of the first 10 patients came from a single Canadian-American Indian family, in whom it was due to a mutation in the $\operatorname{CSB}$ gene. ${ }^{8}$ Infants with this disorder are severely dwarfed with some facial and clinical features reminiscent of CS. The children have microcephaly, microphthalmia, cataracts, retinopathy, micrognathia, hypotonia, flexion contractures of the elbows and knees, generalized osteoporosis, and rocker bottom feet. They also exhibit dramatic growth failure, tiny brains, and most die before age 3 years. As in CS, postmortem examination reveals dilated ventricles, marked myelin attenuation with a tigroid pattern of demyelination, calcific deposits, and a hypoplastic cerebellum with an arachnoidal cyst in the vicinity of the cisterna magna. ${ }^{22,23}$ A child who died at age 7 years had extensive calcification in the brain, with many thickened and narrowed arteries and arterioles. Descriptions of peripheral nerves are lacking and those of skeletal muscle are limited. ${ }^{22}$ Sakai et al. ${ }^{23}$ described neuronal migration defects in a Japanese case, a finding absent in CS. There is no mention of glia with the bizarre, hyperchromatic nuclei of CS. Cultured COFS cells show DNA repair deficits similar to those of CS cells, and the disorder is viewed as allelic to $C S B .^{8}$

\section{Xeroderma pigmentosum neurologic disease}

The hallmark of XP, which is also autosomal recessive, is extreme photosensitivity of the skin and eyes with premature cutaneous aging and a 1000-fold increased frequency of cutaneous basal and squamous cell carcinomas and melanomas, especially in sun-exposed areas. ${ }^{3,4,19,20}$ The skin develops marked freckling and other pigmentation abnormalities. Approximately $20 \%$ of patients with XP worldwide develop XP neurologic disease ${ }^{4,24}$ (see table 2), with a considerably higher rate in Japan. ${ }^{2,19,20,24}$ These neurologic abnormalities result not from a myelinopathy, as in CS, but from the primary degeneration of previously normally developed neurons, with resultant axonopathy and widespread gliosis. ${ }^{3,24}$ Reasons 
for the differing tissue specificity responsible for the development of XP neurologic disease in only a fraction of patients with XP are not understood.

Major signs of neuronal loss in XP neurologic disease are microcephaly and mental retardation or dementia, which are associated with cortical atrophy, ventricular dilation, and EEG abnormalities. ${ }^{4,24}$ Death of corticospinal neurons is responsible for spasticity and extensor plantar responses. Loss of neurons in the basal ganglia and substantia nigra pars compacta may eventuate in movement disorders. Neuronal depletion also affects the locus ceruleus and the cerebellum with resultant ataxia, dysarthria, and abnormal eye movements. Death of neurons in the cord and spinal root ganglia accounts for a mixed sensorimotor distal axonopathy, with typical electromyographic findings and neuropathic changes on muscle biopsy. Audiometry documents a worsening high-frequency hearing loss that signals the progressive death of cochlear hair cells.

Deteriorating hearing and progressive loss of tendon stretch reflexes are the required criteria for a diagnosis of XP neurologic disease. All patients eventually develop virtually the entire constellation of abnormalities, but the age at onset and the rate of progression vary a great deal. Children who develop neurologic disease before age 7 tend to decline rapidly and manifest marked retardation of growth and sexual development. The DeSanctis-Cacchione syndrome $^{3,24}$ refers to the most severe early-onset subtype. There are two juvenile variants in which growth and sexual development are unaffected and progression is slower: the intermediate-onset subtype (onset between ages 7 and 12) and the lateonset subtype (onset after 12 , but prior to 21 ). Recently, a clinically asymptomatic adult variant has also been identified. $^{25}$

Cell fusion analysis has identified seven XP complementation groups (A through G) among patients with nucleotide excision repair deficient XP. ${ }^{2}$ In addition, there is a nucleotide excision repair proficient form of XP, the XP variant (XP-V). ${ }^{2}$ (table 3) There are many patients in XP group A with documented XP neurologic disease, several in group $\mathrm{D}$, and one in group $\mathrm{C}$. The group $\mathrm{C}$ patient was the first with adult-onset XP neurologic disease; she was asymptomatic when it was identified. ${ }^{24,25}$ No patient meeting the criteria for XP neurologic disease has been documented in XP groups B, E, F, G, or the XP-V variant.

Patients who belong to XP complementation group D present with the most diverse phenotypes of any group ${ }^{19}$ (see table 3); in addition to some individuals with XP neurologic disease, this group also includes a few patients with XP-CS complex, and some with trichothiodystrophy, a distinct phenotype. Patients with trichothiodystrophy, itself genetically heterogeneous, ${ }^{26}$ have congenital ichthyosis, brittle sulfur-deficient hair and nails, impaired physical and sexual development, and mental deficiency. Only a fraction have UV sensitivity and none develop skin cancers. ${ }^{2,27,28}$

\section{XP-CS complex}

Eight previously described patients with the XP-CS complex fell into three XP complementation groups (see table 3) and differed greatly in clinical severity. ${ }^{2,3,19,20}$ The three groups result from mutations in different genes: chromosome $2 \mathrm{q} 21$ for group B, chromosome $19 \mathrm{q} 13$ for group $\mathrm{D}$, and chromosome $13 \mathrm{q} 33$ for group $\mathrm{G}$. The XPB and XPD 
proteins act as DNA helicases and are involved in both DNA repair and transcription as part of the basal transcription factor TFIIH. ${ }^{2}$

The three patients with XP-CS complex in XP complementation group B had a much less severe phenotype than those in groups D and G, with survival to at least the fifth decade of life. Their XP phenotype was mild; only one of these three individuals (XP11BE) developed skin cancer and that not until age 18. She had the typical CS loss of subcutaneous fat and beaked nose with dwarfism, along with the pigmentary cutaneous changes of XP. ${ }^{3,13,21}$ The other two patients were adult brothers (XPCS1BA and XPCS2BA) ${ }^{29,30}$ who were not severely dwarfed, as their heights and weights were close to the third percentile (51 kg and $159 \mathrm{~cm} ; 62 \mathrm{~kg}$ and $168 \mathrm{~cm}$ ). They had hypogonadism, prominent incoordination, and lateonset neuropathy with mixed demyelinating and axonal features.

The two children with XP-CS complex in XP complementation group D were very severely affected. ${ }^{31-33}$ One boy (XPCS2) had the severe CS phenotype, including signs of prenatal growth failure (head circumference, weight, and height all below the third percentile at birth). He had multiple skin tumors. The other patient (XP8BR) also met criteria for severe $\mathrm{CS}$, but had only equivocal evidence for prenatal growth failure (height 50 centimeters, weight 2.5 kilograms, and head circumference 32 centimeters). ${ }^{5} \mathrm{He}$ had cryptorchidism, congenital cataracts, pigmentary retinopathy, and enophthalmos and was severely neurologically affected, had skin UV sensitivity, failure to thrive, and died of pneumonia at age 2 without evidence of skin cancer.

The three previously described children with XP-CS complex who belonged to XP complementation group $\mathrm{G}$ also had a very severe CS phenotypes and died at ages 7 months, 1.7, and 6.5 years. ${ }^{34-36}$ These patients had the UV skin sensitivity and freckling of XP, but without skin cancers, perhaps because of their young age at death, as their cells had the biochemical characteristics of XP. The XPG protein functions as an endonuclease that cuts DNA near a lesion. ${ }^{2}$ As in the fourth case summarized below, mutations in these three children with group G XP-CS complex resulted in severe truncation of the XPG protein, ${ }^{36}$ which was not the case in two siblings with group G XP without the CS phenotype. ${ }^{36,37}$ There is evidence that the CS phenotype in the XP-CS complex and in patients with CS without XP may result from the inability to repair oxidative DNA damage. ${ }^{36,38-40}$ There is also evidence of defective repair in XP cells of lesions caused by oxidative DNA damage. ${ }^{41-45}$

\section{The ninth patient with XP-CS complex}

\section{Case history}

This boy, XP20BE, who died at age 6 years 2 months and whose clinical abnormalities are summarized in table 2 , was born at term to nonconsanguineous white parents with unremarkable family histories. He was normal in size, appearance, and head circumference at birth; at age 4 months he developed the first of 10 severe sunburns that occurred despite stringent efforts to avoid exposure to sunlight (figure 1a). His skin became progressively freckled and atrophic but there was no skin cancer (figure 1b). Growth ceased at 21 months. Weight gain slowed at 4 months, ceased at 21 months, and weight decreased after 3 years to 
6.5 kilograms at death. Growth of the head flattened at age 5 months and ceased at 1 year. The facial dysmorphism of CS (figure 1c), including deep-set eyes, small pupils that did not dilate in the dark, sharp nose, and thin lips, became discernable at 15 months when progressive loss of hearing was detected. Pigmentary degeneration of the retina was observed at age 2 years. He did not speak but was alert and sociable to the end. At age 13 months, spinal fluid protein was $99 \mathrm{mg} / \mathrm{dL}$ and there was no calcification or abnormality by CT scan, whereas MRI at age 3 years revealed cerebellar atrophy and moderate ventricular enlargement. He never achieved independent walking, the ability to sit himself up, or toilet training. He became progressively ataxic and spastic, and eventually developed joint contractures (figure 1d). His tendon stretch reflexes were hyperactive with sustained ankle clonus and Babinski's signs until age 4 years, when he lost his ankle jerks and developed progressively severe muscle wasting and the inability to hold his head erect. Nerve conduction velocities at 21 age months indicated an axonal and demyelinating process, and electromyography at age 6 years a mixed neurogenic and myopathic process. Cachexia became profound and he died of pneumonia.

\section{Neuropathology}

A full report of this first neuropathologic study of XP-G/CS will be presented elsewhere. In brief, the fixed brain weighed 350 grams, the expected weight at 36 to 37 weeks of gestation. Although the brain was small, the sulci and gyri were proportionally reduced so that the brain did not appear atrophic. Some of the histopathologic features are illustrated in figure 2. There was no evidence of migration defect or other malformation, but there was neuronal loss in the cortex, basal ganglia, and cerebellum. The white matter was severely attenuated with a tigroid pattern of demyelination. There was diffuse cortical and subcortical gliosis with many bizarre astrocytes and rare binucleated astrocytes, bringing to mind neoplastic transformation, but no evidence of neoplasia. There was ventriculomegaly and patchy fibrosis of the leptomeninges. Parenchymal and vascular calcification, with mild arteriosclerotic medial and adventitial fibrosis, was most prominent in the basal ganglia and diencephalon, but was also present in thalamus, cerebral gray and white matter, and in the cerebellum, where there was Purkinje cell degeneration and Bergmann gliosis. The brainstem was atrophic with enlargement of the aqueduct, fourth ventricle, and cisterna magna. There was advanced myelinopathy and secondary axonal degeneration of the sural nerves. Skeletal muscle had undergone profound atrophy with mixed myopathic and neuropathic changes. Pathology of the eyes included cataracts, iris atrophy, abnormal ciliary processes, retinal pigmentary atrophy, and optic nerve atrophy and gliosis.

\section{Cytogenetic and molecular studies}

Detailed studies of the molecular aspects of this fourth patient with the severe XP-G/CS have been published. ${ }^{46,47}$ The karyotype was normal, but cytogenetic studies revealed a translocation $\mathrm{t}(7 ; 14)(\mathrm{p} 13 ; \mathrm{q} 11.2)$ in one of 70 peripheral blood cells examined (test performed by Dr. Uta Francke, Yale University). Although this translocation is known to occur in $\mathrm{T}$ cells from some normal individuals, it is detected with increased frequency in patients with ataxia-telangiectasia, a disorder with $\mathrm{x}$-ray but not UV hypersensitivity, the cause of which is altered cell cycle regulation rather than defective DNA repair. ${ }^{48}$ 
There was a severe DNA repair defect in cultured skin and blood cells (XP20BE), with markedly reduced unscheduled DNA synthesis after UV exposure (less than 5\% of normal), extreme sensitivity to killing by UV radiation, and increased plasmid mutation frequency after UV exposure. ${ }^{46}$ The cell killing and plasmid mutagenesis findings are consistent with DNA-repair abnormalities common to both XP and CS, but the reduced unscheduled DNA synthesis after UV exposure is only observed in XP. Cell fusion studies assigned XP20BE to $\mathrm{XP}$ complementation group G. DNA sequencing of the $X P G$ gene in this boy revealed a $\mathrm{G}$ to $T$ mutation in exon 1 that converted a glutamic acid at codon 11 to a termination codon, thereby resulting in a markedly truncated XPG protein. ${ }^{47}$

\section{Conclusion}

This review indicates how much more there is to learn about genotype-phenotype correlations in the overlapping disorders characterized at the molecular level by inadequate DNA repair. Why is it that all CS and some, but not all, XP mutations affect the CNS? Why do all CS but only some XP mutations affect neuronal survival, and do so to such variable extents? Why do the CS and some XP mutations accelerate the aging process so severely? The $X P B$ and $X P D$ genes participate in transcription in addition to repair, and this dual role may provide an explanation for the combined XP group B-CS and XP group D-CS complex phenotypes, but there is little evidence that XPG plays a role in transcription, despite the XP-G/CS phenotype of some patients with XP group G disease. Also, why do XPD mutations that result in the clinically distinct trichothiodystrophy syndrome not result in skin cancers, even in patients with enhanced UV sensitivity?

Type II CS, in its classic variant, in COFS syndrome, and in the infantile XP-CS complex forms, is one of the most severely dwarfing diseases known. An explanation for the drastic postnatal curtailment of somatic and brain growth is lacking. Tissue specificity, with neurons bearing the brunt of the disease in XP, and myelin as well as neurons in CS and XPCS complex requires investigation. How defective DNA repair leads to progressive degeneration of cells not exposed to UV radiation, and especially of nondividing cells like neurons and cochlear cells, is not fully understood but has been attributed to inadequate repair of oxidative damage resulting from normal metabolism. ${ }^{49}$ Defective repair of oxidative DNA damage resulting from normal metabolism in cells not exposed to UV radiation, and especially in nondividing cells like neurons and cochlear cells, may induce apoptosis. ${ }^{49}$ Potentially, administration of antioxidants or free radical scavengers might prevent or mitigate deficient ability to repair oxidative damage. Unraveling the pathophysiology of CS may further our understanding of the control of postnatal growth and of the aging process, as insight into other disorders of DNA repair such as classic XP and of cell cycle dysregulation in ataxia-telangiectasia has contributed to illuminating carcinogenesis.

\section{Acknowledgment}

The authors thank the child's parents for their cooperation and understanding of the importance of making it possible for their child to contribute to advancing knowledge about the biology of his devastating illness. They also thank Dr. Donald Wight, who referred and cared for the patient; Drs. Roger Brumback and Carlos Luciano, for assistance in his evaluation; Dr. Craig Disse, who performed the autopsy; and Dr. Pearl Rosenbaum, who contributed data on the pathology of the eyes. 


\section{References}

1. Cockayne EA. Dwarfism with retinal atrophy and deafness. Arch Dis Child. 1936; 21:52-54.

2. Cleaver JE, Thompson LH, Richardson AS, States JC. A summary of mutations in the UV-sensitive disorders: xeroderma pigmentosum, Cockayne syndrome, and trichothiodystrophy. Hum Mutat. 1999; 14:9-22. [PubMed: 10447254]

3. Robbins JH, Kraemer KH, Lutzner MA, Festoff BW, Coon HG. Xeroderma pigmentosum. An inherited disease with sun sensitivity, multiple cutaneous neoplasms, and abnormal DNA Repair. Ann Intern Med. 1974; 80:221-248. [PubMed: 4811796]

4. Robbins JH. Xeroderma pigmentosum. Defective DNA repair causes skin cancer and neurodegeneration. JAMA. 1988; 260:384-388. [PubMed: 3379749]

5. Nance MA, Berry SA. Cockayne syndrome: review of 140 cases. Am J Med Genet. 1992; 42:68-84. [PubMed: 1308368]

6. Soffer D, Grotsky HW, Rapin I, Suzuki K. Cockayne syndrome: unusual neuropathological findings and review of the literature. Ann Neurol. 1979; 6:340-348. [PubMed: 400082]

7. Stefanini M, Fawcett H, Botta E, Nardo T, Lehmann R. Genetic analysis of twenty-two patients with Cockayne syndrome. Hum Genet. 1996; 97:418-423. [PubMed: 8834235]

8. Meira LB, Graham JM, Greenberg C, et al. Manitoba aboriginal kindred with original cerebrooculo-facio-skeletal syndrome has a mutation in the Cockayne syndrome group B (CSB) gene. Am J Hum Genet. 2000; 66:1221-1228. [PubMed: 10739753]

9. Evrard, P.; de Saint-Georges, P.; Kadhim, HJ.; Gadisseux, J-F. Pathology of prenatal encephalopathies. In: French, JH.; Harel, S.; Casaer, P., et al., editors. Child neurology and developmental disabilities. Baltimore: Paul Brookes; 1989. p. 153-176.

10. McKusick VA, Mahloudji M, Abbott MH, Lindenberg R, Kepas D. Seckel's bird-headed dwarfism. N Engl J Med. 1967; 277:279-286. [PubMed: 4378248]

11. Gandolfi A, Horoupian D, Rapin I, DeTeresa R, Hyams V. Deafness in Cockayne's syndrome: morphological, morphometric, and quantitative study of the auditory pathway. Ann Neurol. 1984; 15:135-143. [PubMed: 6703654]

12. Neill CA, Dingwall MM. A syndrome resembling progeria: a review of two cases. Arch Dis Child. 1950; 25:213-221. [PubMed: 14783428]

13. Brumback RA, Yoder FW, Andrews AD, Peck GL, Robbins JH. Normal pressure hydrocephalus: recognition and relationship to neurological abnormalities in Cockayne's syndrome. Arch Neurol. 1978; 35:337-345. [PubMed: 655905]

14. Kohji T, Hayashi M, Shioda K, et al. Cerebellar neurodegeneration in human hereditary DNA repair disorders. Neurosci Lett. 1998; 243:133-136. [PubMed: 9535131]

15. Leech RW, Brumback RA, Miller RH, Otsuka F, Tarone RE, Robbins JH. Cockayne syndrome: clinicopathologic and tissue culture studies of affected siblings. J Neuropathol Exp Neurol. 1985; 44:507-519. [PubMed: 4031953]

16. Cervos-Navarro, J.; Urich, H. Metabolic and degenerative diseases of the nervous system: pathology, biochemistry and genetics. San Diego: Academic Press; 1995.

17. Scudiero DA, Moshell AM, Scarpinato RG, et al. Lymphoblastoid lines and skin fibroblasts from patients with tuberous sclerosis are abnormally sensitive to ionizing radiation and to radiomimetic chemicals. J Invest Dermatol. 1982; 78:234-238. [PubMed: 7057056]

18. Tretiakova A, Krysnka B, Gordon J, Khalili K. Human neurotropic JC virus early protein deregulates glial cell cycle pathway and impairs cell differentiation. J Neurosci Res. 1999; 55:588-599. [PubMed: 10082081]

19. Kraemer KH, Lee MM, Scotto J. Xeroderma pigmentosum. Cutaneous, ocular, and neurologic abnormalities in 830 published cases. Arch Dermatol. 1987; 123:241-250. [PubMed: 3545087]

20. Kraemer, KH. Heritable diseases with increased sensitivity to cellular injury. In: Freedberg, IM.; Eisen, AZ.; Wolff, K., et al., editors. Fitzpatrick's dermatology in general medicine. New York: McGraw Hill; 1999. p. 1848-1862. 
21. Lowry RB, MacLean R, McLean DM, Tischler B. Cataracts, microcephaly, kyphosis, and limited joint movement in two siblings: a new syndrome. J Pediatr. 1971; 79:282-284. [PubMed: 5560051]

22. Del Bigio MR, Greenberg CR, Rorke LB, Schnur R, McDonald-McGinn DM, Zackai EH. Neuropathological findings in eight children with cerebro-oculo-facio-skeletal (COFS) syndrome. J Neuropathol Exp Neurol. 1997; 56:1147-1157. [PubMed: 9329459]

23. Sakai T, Kikuchi F, Takashima S, Matsuda H, Watanabe N. Neuropathological findings in the cerebro-oculo-facio-skeletal (Pena-Shokeir II) syndrome. Brain Dev. 1997; 19:58-62. [PubMed: 9071492]

24. Robbins JH, Brumback RA, Mendiones M, et al. Neurological disease in xeroderma pigmentosum. Documentation of a late onset type of the juvenile onset form. Brain. 1991; 114:1335-1361. [PubMed: 2065254]

25. Robbins JH, Brumback RA, Moshell AN. Clinically asymptomatic xeroderma pigmentosum neurological disease in an adult: evidence for a neurodegeneration in later life caused by defective DNA repair. Eur Neurol. 1993; 33:188-190. [PubMed: 8467834]

26. Weeda G, Eveno I, Donker W, et al. A mutation in the XPB/ERCC3 DNA repair transcription gene, associated with trichothiodystrophy. Am J Hum Genet. 1997; 60:320-329. [PubMed: 9012405]

27. Taylor EM, Broughton BC, Botta E, et al. Xeroderma pigmentosum and trichothiodystrophy are associated with different mutations in the XPD (ERCC2) repair/transcription gene. Proc Natl Acad Sci USA. 1997; 94:8658-8663. [PubMed: 9238033]

28. Stefanini M, Lagomarsini P, Giliani S, et al. Genetic heterogeneity of the excision repair defect associated with trichothiodystrophy. Carcinogenesis. 1993; 14:1101-1105. [PubMed: 8508495]

29. Scott RJ, Itin P, Kleijer WJ, Kolb K, Arlett C, Muller H. Xeroderma pigmentosum-Cockayne syndrome complex in two patients: absence of skin tumors despite severe deficiency of DNA excision repair. J Am Acad Dermatol. 1993; 29:883-889. [PubMed: 8408834]

30. Vermeulen W, Scott RJ, Rodgers S, et al. Clinical heterogeneity within xeroderma pigmentosum associated with mutations in the DNA repair and transcription gene ERCC3. Am J Hum Genet. 1994; 54:191-200. [PubMed: 8304337]

31. Lafforet D, Dupuy J-M. Photosensitization and DNA repair. Possible nosologic relationship between xeroderma pigmentosum and Cockayne's syndrome [French]. Arch Fr Pediatr. 1978; 35(suppl):65-74. [PubMed: 749755]

32. Broughton BC, Thompson AF, Harcourt SA, et al. Molecular and cellular analysis of the DNA repair defect in a patient in xeroderma pigmentosum complementation group $\mathrm{D}$ who has the clinical features of xeroderma pigmentosum and Cockayne syndrome. Am J Hum Genet. 1995; 56:167-174. [PubMed: 7825573]

33. Vermeulen W, Stefanini M, Giliani S, Hoeijmakers JHJ, Bootsma D. Xeroderma pigmentosum group H falls into complementation group D. Mutat Res. 1991; 255:210-208.

34. Vermeulen W, Jaeken J, Jaspers NG, Bootsma D, Hoeijmakers JH. Xeroderma pigmentosum complementation group G associated with Cockayne syndrome. Am J Hum Genet. 1993; 53:185192. [PubMed: 8317483]

35. Hamel BCK, Raams A, Schuitema-Dijkstra AR, et al. Xeroderma pigmentosum-Cockayne syndrome complex. A further case. J Med Genet. 1996; 33:607-610. [PubMed: 8818951]

36. Nouspikel T, Lalle P, Leadon SA, Cooper PK, Clarkson SG. A common mutational pattern in Cockayne syndrome patients from xeroderma pigmentosum group G: implications for a second XPG function. Proc Natl Acad Sci USA. 1997; 94:3116-3121. [PubMed: 9096355]

37. Norris PG, Hawk JL, Avery JA, Giannelli F. Xeroderma pigmentosum complementation group G —report of two cases. Br J Dermatol. 1987; 116:861-866. [PubMed: 3620347]

38. Klungland A, Hoss M, Gunz D, Constantinou A, et al. Base excision repair of oxidative DNA damage activated by XPG protein. Mol Cell. 1999; 3:33-42. [PubMed: 10024877]

39. Cooper PK, Nouspikel T, Clarkson SG, Leadon SA. Defective transcription-coupled repair of oxidative damage in Cockayne syndrome patients from XP group G. Science. 1997; 275:990- 993. [PubMed: 9020084] 
40. Le Page F, Kwoh EE, Avrutskaya A, et al. Transcription-coupled repair of 8-oxoguanine: requirements for XPG, TFIIH, and CSB and implications for Cockayne syndrome. Cell. 2000; 101:159-171. [PubMed: 10786832]

41. Parshad RP, Sanford KK, Price FM, et al. Fluorescent light-induced chromatic breaks distinguish Alzheimer disease cells from normal cells in tissue culture. Proc Natl Acad Sci USA. 1996; 93:5146-5150. [PubMed: 8643543]

42. Satoh MS, Jones CJ, Wood RD, Lindahl T. DNA excision-repair defect of xeroderma pigmentosum prevents removal of a class of oxygen free radical-induced base lesions. Proc Natl Acad Sci USA. 1993; 90:6335-6339. [PubMed: 8327515]

43. Reardon JT, Bessho T, Kung HC, Bolton PH, Sancar A. In vitro repair of oxidative DNA damage by human nucleotide excision repair systems: possible explanation for neurodegeneration in xeroderma pigmentosum patients. Proc Natl Acad Sci USA. 1997; 94:9463-9468. [PubMed: 9256505]

44. Kuraoka I, Bender C, Romieu A, Cadet J, Wood RD, Lindahl T. Removal of oxygen free-radicalinduced 8,5'-purine cyclodeoxynucleosides from DNA by the nucleotide excision-repair pathway in human cells. Proc Natl Acad Sci USA. 2000; 97:3832-3837. [PubMed: 10759556]

45. Brooks PJ, Wise DS, Berry DA, et al. The oxidative DNA lesion 8,5-cyclo-2'-deoxyadenosine is repaired by the nucleotide excision repair pathway and blocks gene expression in mammalian cells. J Biol Chem. 2000; 275:22355-22362. [PubMed: 10801836]

46. Moriwaki S, Stefanini M, Lehmann AR, et al. DNA repair and ultraviolet mutagenesis in cells from a new patient with xeroderma pigmentosum group $\mathrm{G}$ and Cockayne syndrome resemble xeroderma pigmentosum cells. J Invest Dermatol. 1996; 107:647-653. [PubMed: 8823375]

47. Okinaka RT, Perez-Castro AV, Sena A, et al. Heritable genetic alterations in a xeroderma pigmentosum group G/Cockayne syndrome pedigree. Mutat Res. 1997; 385:107-114. [PubMed: 9447232]

48. Sedgwick S, Collins A. Recent advances in DNA repair: a report of a meeting of the British Photobiology Society and the DNA Repair Network. London, 14 and 15 December 1990. Mutat Res. 1991; 255:101-110. [PubMed: 2067548]

49. Hanawalt PC. The bases for Cockayne syndrome. Nature. 2000; 405:415-416. [PubMed: 10839526] 

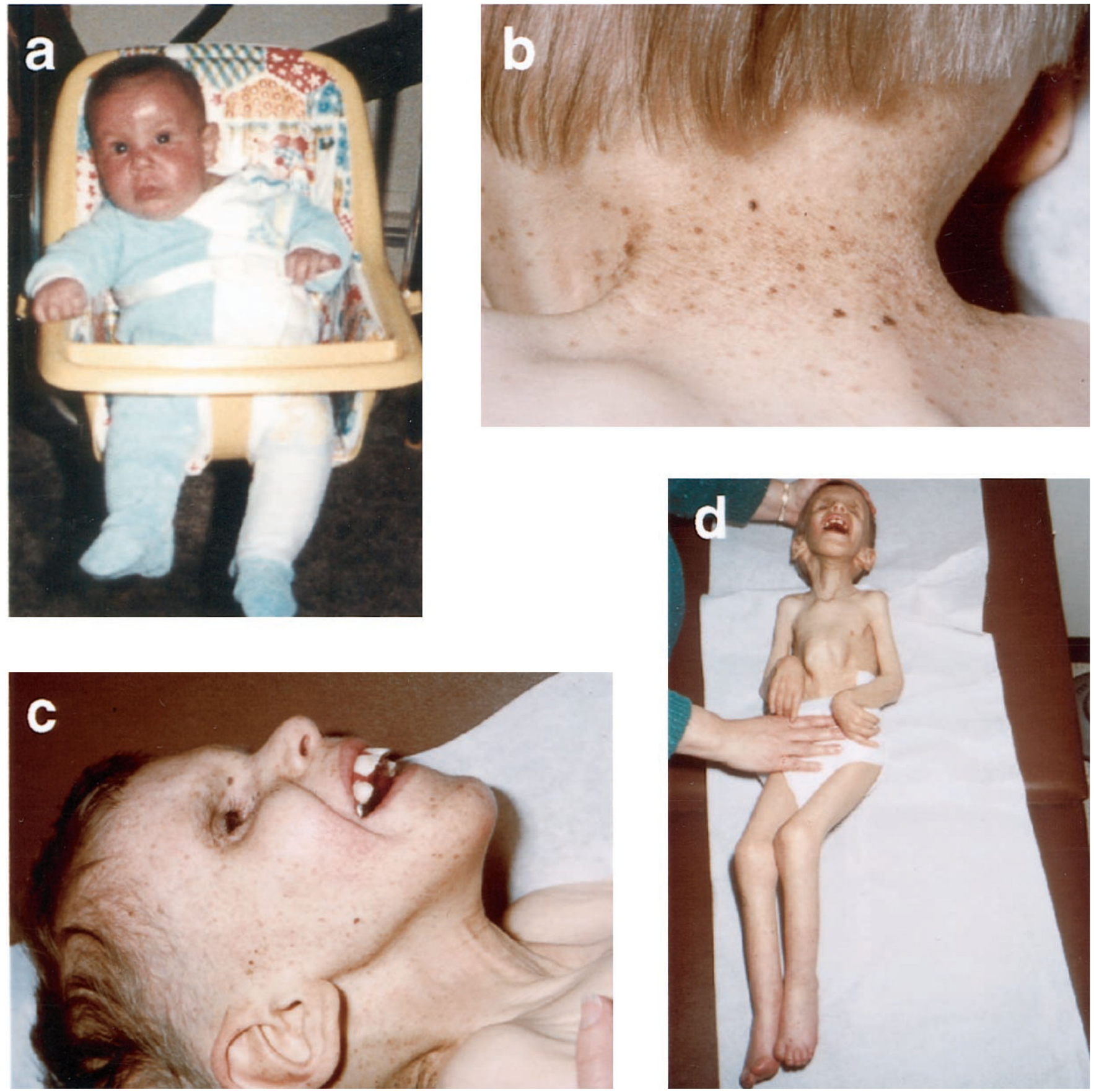

Figure 1.

(a) Patient XP20BE at age 4 months after he developed a severe sunburn in March — the first sign of illness. (b) Characteristic skin lesions: freckling, hypopigmented macules, telangiectasias, and atrophic skin. (c) Typical Cockayne syndrome facies at age 6 years. (d) Contractures and profound cachexia at age 6 years. 

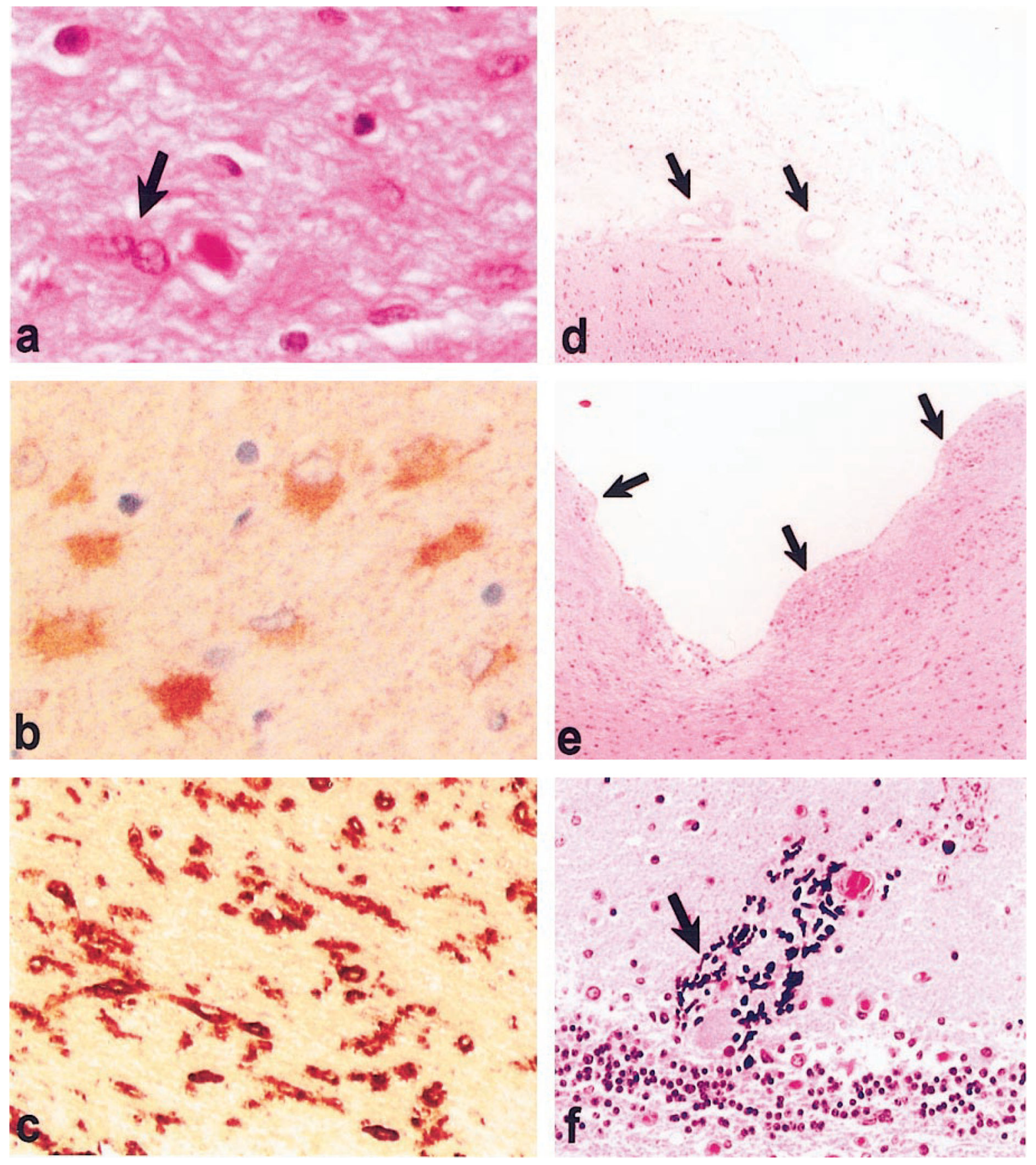

Figure 2.

(a) Hematoxylin-eosin-stained section of white matter shows fibrillary gliosis and rare binucleated astrocytes (arrow). (b) Glial fibrillary acidic protein immunostaining of white matter shows prominent reactive astrocytes. (c) Ricinus lectin histochemistry of white matter shows prominent microgliosis in white matter. (d) Hematoxylin-eosin-stained section of leptomeninges shows thickened fibrotic meninges and arteries with fibrotic and thick walls (inset). (e) Hematoxylin-eosin-stained section of ependymal lining shows focal denudation of ependyma with glial overgrowth typical of granular ependymitis 
(arrowheads). (f) Hematoxylin-stained calcification in dystrophic neuronal processes in the cerebellum. (Basal ganglia calcification was also prominent.) 
Table 1

Comparison of laboratory abnormalities in cells from patients with CS, XP neurologic disease, and XP-G/CS

\begin{tabular}{|c|c|c|c|}
\hline Laboratory abnormalities & CS & XP neurologic disease & $\begin{array}{c}\text { XP-G/CS } \\
\text { (XP20BE) } \\
\text { (current case) }\end{array}$ \\
\hline Hypersensitivity to killing by UV & Present & Present & Present \\
\hline $\begin{array}{l}\text { Unscheduled DNA synthesis after UV } \\
\text { exposure }\end{array}$ & Normal & Low & Very low ${ }^{*}$ \\
\hline Recovery of RNA synthesis after UV exposure & Mildly reduced, dose-related & $\begin{array}{c}\text { Severely reduced in XP-A, XP-D, XP- } \\
\text { G; normal in XP-C }\end{array}$ & Severely reduced ${ }^{\dagger}$ \\
\hline \multicolumn{4}{|l|}{ Similar to the post-UV survival of the XP-A cells. } \\
\hline
\end{tabular}


Table 2

Comparison of clinical features of patients with CS, COFS syndrome, XP neurologic disease, and the current child with XP-G/CS

\begin{tabular}{lcccc}
\hline Clinical features & CS & COFS syndrome & XP neurologic disease & $\begin{array}{c}\text { XP-G/CS } \\
\text { (XP20BE) }\end{array}$ \\
\hline Sun sensitivity & Yes & $?$ & Yes & Yes \\
Increased freckling & No & No & Yes & Yes \\
Skin cancers & No & No & Yes & No \\
Cachectic dwarfism & Yes & Yes & Yes/no & Yes \\
Microcephaly & Yes & Yes & Yes & Yes \\
Progressive cognitive impairment & Yes & Yes & Yes & Yes \\
Sensorineural deafness & Yes & Yes & Yes & Yes \\
Anterior eye abnormalities & Yes & Yes & Yes & Yes \\
Retinal degeneration & Yes & Yes & No & Yes \\
Skeletal abnormalities & Yes/no & Yes & No & Yes \\
Spasticity & Yes & Yes & Yes/no & Yes \\
Ataxia & Yes & Yes & Yes & Yes \\
Axonal neuropathy & No & $?$ & Yes & Yes \\
Demyelinating neuropathy & Yes & $?$ & No & Yes \\
Myopathy & No & Yes? & No & Yes \\
Brain calcification & Yes & Yes & No & Yes \\
Elevated CSF protein & Yes & $?$ & No & Yes \\
\hline
\end{tabular}

$\mathrm{CS}=$ Cockayne syndrome; $\mathrm{COFS}=$ cerebro-oculo-facial-skeletal $; \mathrm{XP}=$ xeroderma pigmentosum; yes $/ \mathrm{no}=$ not present in all cases; $?=$ no information. 

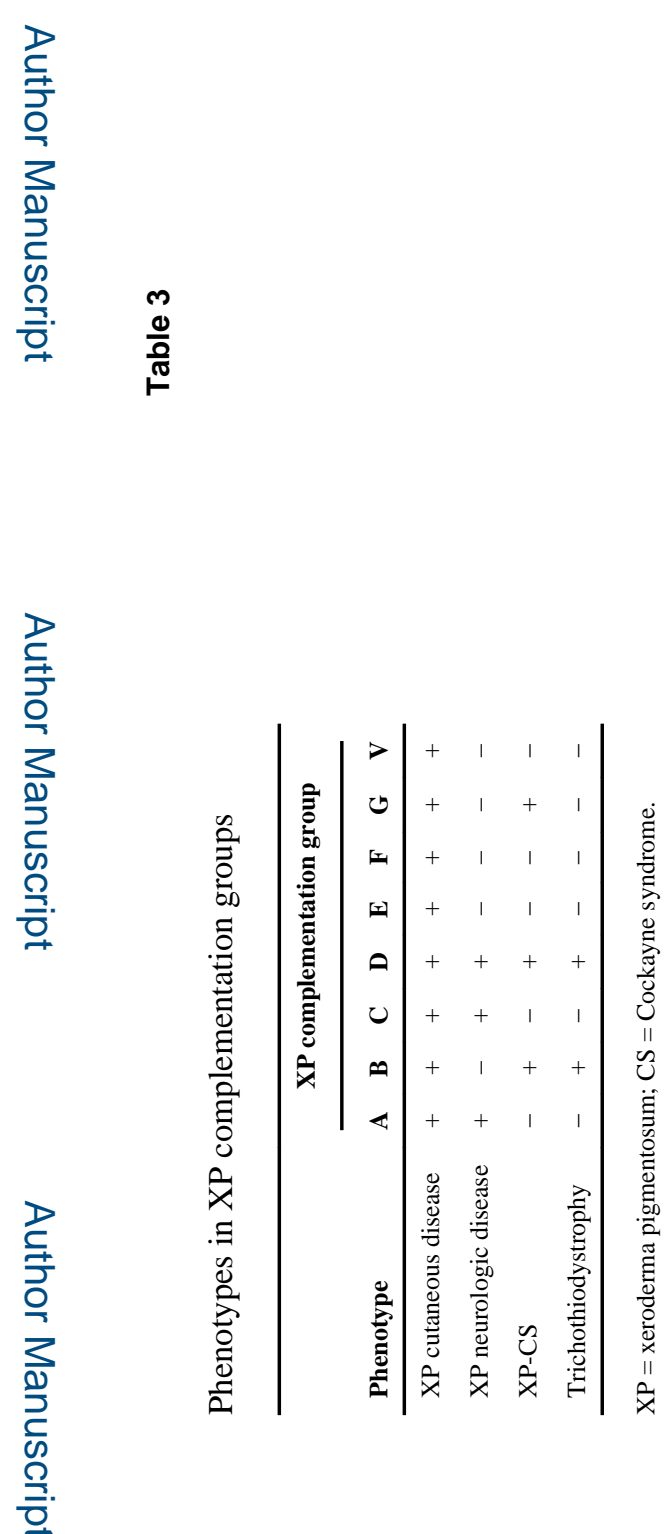

Neurology. Author manuscript; available in PMC 2015 June 08. 